\title{
La Audiencia de Pacto de Cumplimiento en las Acciones Populares y las Sanciones por Inasistencia del Demandante
}

\section{Hearing on class actions and sanctions for absence of the complainant}

\section{RESUMEN}

El presente artículo refleja un estudio jurídico-práctico de las implicaciones que conlleva la inasistencia del actor popular a la audiencia especial de pacto de cumplimiento prevista en el Artículo 27 de la Ley 472 de 1998.

Se trata de explicar, con un lenguaje sencillo pero preciso, si como lo han interpretado algunas instancias judiciales es posible imponer sanciones por la inasistencia al actor popular, dado que se advierte cierta ambigüedad en la comprensión del problema y que por desconexión con principios y garantías procesales es bastante cuestionable.

Para tal efecto, el autor realiza un recorrido normativo y jurisprudencial, para profundizar en el análisis de la improcedencia de la sanción pecuniaria que se viene imponiendo al actor popular que por alguna razón no asiste a la audiencia de pacto de cumplimiento, a la cual previamente ha sido citado por el juez que tramita una acción popular.

Igualmente, merecerá especial análisis si procede el grado de consulta del auto que se expide en este especial trámite procesal.

\section{PALABRAS CLAVE}

Acciones populares, debido proceso, derecho de defensa, sanción, pacto de cumplimiento.

\section{ABSTRACT}

The author explains in the article the different interpretations that judges have made the absence of the complainant class action. This topic presents some ambiguity and diversity criteria.

This article is a normative and jurisprudential description for further analysis of the inadmissibility of the financial penalty on the complainant.

\section{KEYWORDS}

Popular actions, due process, rigth to defense, sanction, Covenant compliance. 


\section{INTRODUCCIÓN}

Al entrar en vigencia la Ley 1437 de 2011, "Por la cual se expide el Código de Procedimiento Administrativo y de lo Contencioso Administrativo", y teniendo en cuenta la Constitución Política y otras disposiciones legales, en especial las que posteriormente fueron expedidas a la Ley 1437 , que directa e indirectamente han incidido en sus disposiciones, tales como la Ley 1450 de 2011, "Por la cual se expide el Plan Nacional de Desarrollo, 2010-2014" y la Ley 1564 de 2012', "Por medio de la cual se expide el Código General del Proceso y se dictan otras disposiciones", surgen dudas acerca de la eventual derogatoria tácita de ciertas disposiciones legales que regulan trámites 0 procesos especiales, como lo son las que dinamizan las acciones populares.

Surge la inquietud, por demás interesante, desde la perspectiva del derecho procesal administrativo, teniendo en cuenta la implementación gradual de la normatividad que antecede, establecer si es jurídico sancionar con multa al actor popular por no asistir a la audiencia especial de pacto de cumplimiento prevista en el Art. 27 de la Ley 472 de 1998 y así mismo, establecer si la decisión que el juez dicte en ese sentido debe ser consultada ante el superior jerárquico.

Lo anterior, en tanto se considera lesivo a los derechos fundamentales del debido proceso y al derecho de defensa, incluso regresivo a la finalidad de las acciones populares, imponer dicha sanción al actor popular en ese caso, pues no se verifica la previa identificación legal de la conducta y no se define a plenitud la sanción que sigue a esa omisión. Se conocen algunas decisiones judiciales que imponen multa al actor popular por esta razón, que generan dudas e inseguridad, pues al revisarlas no se encuentran verdaderos y sólidos argumentos jurídicos para ello.

De tal manera que es importante examinar a fondo el asunto y diseñar o delimitar un concepto que se ajuste al orden jurídico interno, en especial, definir si una sanción de esta naturaleza se ajusta a la ley vigente y a las demás normas concordantes, y si se cumple uno de los fines esenciales del Estado Social de Derecho, como lo es brindar garantías y efectividad a los principios, derechos y deberes consagrados en la Constitución (Vila, 2007).

\section{LA AUDIENCIA DE PACTO DE CUMPLIMIENTO}

Debe indicarse preliminarmente que las acciones populares fueron constitucionalizadas a partir de 1991 y se erigieron como uno de los mecanismos de protección de los derechos fundamentales, colectivos y de grupo o de clase, junto con la acción de tutela, la acción de cumplimiento y las acciones de grupo - Artículos 86, 87 y 88-. Las acciones populares y de grupo fueron desarrolladas por la Ley 472 de 1998 (Vila, 2007).

En la actualidad, ante la nueva codificación y marco general del sistema oral mixto de la justicia contenciosa administrativa, las acciones pasaron a denominarse medios de control, pues se quiso evitar la pluralidad de acciones y con ello se concretó que el Art. 144 como medio de control de protección de Ios derechos e intereses colectivos (Palacio, 2013).

Al respecto, la Corte Constitucional en sentencia C-630 del año 2011 señaló:

La jurisprudencia constitucional ha recordado que la acción popular es un derecho político constitucional, en el contexto de una sociedad que se erige como democrática y que defiende a las personas frente a intrusiones ilegítimas de los derechos, sin importar a qué tipo de poder sean adjudicables. Ha recordado que la acción popular es uno de aquellos "[...] instrumentos que forman parte del conjunto de mecanismos que el movimiento constitucionalista occidental contemporáneo ha ido incorporando de manera paulatina a los sistemas jurídicos, para optimizar los medios de defensa de las personas frente a los poderes del Estado, de la administración pública y de los grupos económicamente más fuertes

1 Sobre el impacto del Código General del Proceso en la jurisdicción contenciosa administrativa puede consultarse a Fernando Arias García en "Estudios de Derecho Procesal Administrativo: Ley 1437 de 2011 y código general del proceso". 


\section{$(\ldots)$}

Por su parte, Botero (2004), señaló:

A pesar de su funcionalidad bifronte, la consagración normativa de esta acción se justifica realmente en su faceta preventiva, cuyo objeto es detener el previsible desenvolvimiento causal del daño contingente al daño cierto del interés colectivo, impidiendo su materialización y, en últimas, evitando su real afectación. Todo sobre la base de la difícil reparación de esos derechos, pues normalmente su satisfacción por equivalente no restituye ni compensa en forma plena el interés lesionado y su restablecimiento in natura es en muchos casos imposible. Esta necesidad de prevención tan propia de la acción popular, se ha constituido en un reto adicional para nuestro sistema jurídico, acostumbrado por años a ser árbitro de conflictos y daños consumados, (p. 5).

Con razón se señala que las acciones popularestienen su fundamento en la consagración constitucional de la democracia participativa, pues sin duda alguna la participación de la comunidad en la gestión social y pública genera otros caminos para la prosperidad y el desarrollo armónico de la sociedad.

De acuerdo a Sarmiento, G. (1989) la naturaleza y el contenido de estas acciones se define como:

LAS ACCIONES POPULARES son los remedios procesales colectivos frente a los agravios y perjuicios públicos. A través de ellas cualquier persona, perteneciente a un grupo de la comunidad, está legitimada procesalmente para defender al grupo afectado por unos hechos o conductas comunes, con lo cual simultáneamente protege su propio interés, y obtiene en ciertos casos el beneficio adicional de la recompensa otorgada en determinados eventos por la ley.

Según la Ley 472 de 1998, las acciones populares tienen un trámite especial, es decir, no es el mismo proceso ordinario contencioso administrativo o civil ordinario y en esa perspectiva se prevé que una vez notificado el auto admisorio a la autoridad pública demandada y/o al particular, cuando sea el caso, y se hayan citado a las demás autoridades que tengan relación de protección con alguno de los derechos colectivos mencionados, dentro de los tres días siguientes al vencimiento del traslado, el Juez citará a las partes y al Ministerio Público a una audiencia especial llamada "de pacto de cumplimiento", cuya única finalidad es lograr un consenso entre el actor popular y los funcionarios encargados y competentes que procure y garantice el derecho colectivo que eventualmente esté siendo amenazado o vulnerado por la acción u omisión de la autoridad convocada.

El artículo 44 de dicha ley dispone que:

En los procesos por acciones populares se aplicarán las disposiciones del Código de Procedimiento Civil y del Código Contencioso Administrativo dependiendo de la jurisdicción que le corresponda, en los aspectos no regulados en la presente ley, mientras no se opongan a la naturaleza y la finalidad de tales acciones.

En consecuencia, a las acciones populares que se inicien en la jurisdicción contencioso administrativa con posterioridad al 2 de julio de 2012, fecha en que entró a regir la Ley 1437 de 2011, nuevo Código de Procedimiento Administrativo y de lo Contencioso Administrativo, se les aplicará estas nuevas disposiciones, obviamente, en los aspectos no regulados y si no se oponen a la naturaleza de las acciones populares. Lo mismo ha de decirse de las acciones populares que se tramiten ante la jurisdicción ordinaria, cuando definitivamente ingresen al ordenamiento jurídico las normas que implementan el nuevo sistema oral procesal en Colombia, organizadas en la Ley 1564 de 2012.

Por tanto, a efectos de definir la legalidad de la decisión que impone esta sanción al actor popular, es necesario es determinar si la actuación se inició antes o después de la vigencia de las Leyes 1437 de 2011 y 1564 de 2012.

\section{OBLIGACIÓN DE ASISTIR -CITACIÓN - SANCIONES.}

Al ser este el tema objeto de estudio, resulta entonces necesario citar los textos legales que regulan el tema: 
Art. 27 de la Ley 472 de 1998:

Pacto de cumplimiento. El juez, dentro de los tres (3) días siguientes al vencimiento del término de traslado de la demanda, citará a las partes y al Ministerio Público a una audiencia especial en la cual el juez escuchará las diversas posiciones sobre la acción instaurada, pudiendo intervenir también las personas naturales 0 jurídicas que hayan registrado comentarios escritos sobre el proyecto.

La intervención del Ministerio Público y de la entidad responsable 0 de velar por el derecho 0 interés colectivo será obligatoria.

La inasistencia a esta audiencia por parte de los funcionarios competentes, hará que incurran en causal de mala conducta, sancionable con destitución del cargo.

Si antes de la hora señalada para la audiencia, alguna de las partes presenta prueba siquiera sumaria de una justa causa para no comparecer, el juez señalará nueva fecha para la audiencia, no antes del quinto día siguiente ni después del décimo día, por auto que no tendrá recursos, sin que pueda haber otro aplazamiento.

En dicha audiencia podrá establecerse un pacto de cumplimiento a iniciativa del juez en el que se determine la forma de protección de los derechos e intereses colectivos y el restablecimiento de las cosas a su estado anterior, de ser posible.

El pacto de cumplimiento así celebrado será revisado por el juez en un plazo de cinco (5) días contados a partir de su celebración. Si observare vicios de ilegalidad en alguno de los contenidos del proyecto de pacto, estos serán corregidos por el juez con el consentimiento de las partes interesadas.

La audiencia se considerará fallida en los siguientes eventos:

- Cuando no compareciere la totalidad de las partes interesadas;

- Cuando no se formule proyecto de pacto de cumplimiento, y

- Cuando las partes no consientan en las correcciones que el juez proponga al proyecto de pacto de cumplimiento (...)
Por otra parte, el artículo 41 de la misma ley señala:

DESACATO. La persona que incumpliere una orden judicial proferida por la autoridad competente en los procesos que se adelanten por acciones populares, incurrirá en multa hasta de cincuenta (50) salarios mínimos mensuales con destino al Fondo para la Defensa de los Derechos e Intereses Colectivos, conmutables en arresto hasta de seis (6) meses, sin perjuicio de las sanciones penales a que hubiere lugar.

La sanción será impuesta por la misma autoridad que profirió la orden judicial, mediante trámite incidental y será consultada al superior jerárquico, quien decidirá en el término de tres (3) días si debe revocarse 0 no la sanción. La consulta se hará en efecto devolutivo.

Entonces, un primer aspecto de controversia y duda es definir si la decisión que impone sanción de multa al actor popular por no asistir a tal audiencia de pacto debe y puede ser objeto de consulta ante el superior jerárquico de quien profiere esta decisión, dado que ha sido recurrente enviar estas decisiones al superior jerárquico para que se surta esta instancia, sea el Tribunal Administrativo del sitio donde funcione el Juzgado o el Consejo de Estado, cuando la acción popular se surte en esta jurisdicción. ${ }^{2}$

Es posible decir que tal providencia judicial, como auto interlocutorio que es y de llegarse a proferir para sancionar al actor popular por no asistir a la audiencia de pacto, no es consultable ante el superior jerárquico y no puede sustentarse en el artículo 41 de la Ley 472 de 1998, dado que esta norma solo autoriza sancionar, previo incidente, a quien incumpla una orden judicial, y por ello, no puede extenderse y ampliarse al supuesto de la inasistencia del actor popular a la audiencia de pacto de cumplimiento, pues la simple citación a una audiencia, no puede asimilarse a una "orden judicial", bajo el entendido de que el auto que fija fecha y hora para la realización de la audiencia de pacto, es de simple trámite y sólo implica una invitación al actor popular para que asista a una audiencia en la que con la participación activa del Juez y la anuencia de la autoridad accionada,

2 Recuérdese que según el Art. 16 de la citada ley: "De las Acciones Populares conocerán en primera instancia los jueces administrativos y los jueces civiles de circuito. En segunda instancia la competencia corresponderá a la sección primera del Tribunal Contencioso Administrativo o a la Sala Civil del Tribunal de Distrito Judicial al que pertenezca el Juez de primera instancia." 
adopte, acepte 0 acoja el compromiso que para el efecto exponga la autoridad y que tenga la finalidad de proteger el o los derechos colectivos involucrados. Asimismo, tampoco encuentra respaldo jurídico el grado de consulta si se tiene en cuenta que solo son objeto de este trámite de revisión los autos 0 decisiones que dispone el legislador y por remisión legal no sería posible acudir a este mecanismo. ${ }^{3}$

En estricto derecho y acorde con claros principios y valores fundantes de la organización política colombiana, que dan sentido al debido proceso y el derecho de defensa, con mayor razón tratándose de aspectos que tienen que ver con el poder de corrección y sancionador, el auto interlocutorio que así lo disponga no es consultable y habría una falta de competencia para conocer del mismo en segunda instancia.

El segundo aspecto y el de mayor relevancia, es establecer si la decisión de imponer sanción al actor popular por no asistir a la audiencia de pacto de cumplimiento, encuentra respaldo legal y constitucional. Pues como bien se lee, el Art. 27 de la Ley 472, antes citado, expresamente prevé:

(i) que habrá sanción ÚNICAMENTE - y así debe entenderse-para los funcionarios competentes que no asisten a la audiencia de pacto, (ii) que cualquiera de las partes puede justificar sumariamente la imposibilidad de asistir a la misma y (iii) que el Juez debe considerar FALLIDA la audiencia cuando "no compareciere la totalidad de las partes interesadas".

De ninguna manera pueden entenderse 0 extenderse a otros efectos jurídicos y menos, interpretarse que habrá sanción de multa al actor popular si no asiste a la citada audiencia, pues la ley es clara en este aspecto y cuando ello es así, no se admite interpretación distinta.

Ahora bien, en el caso de los funcionarios que no asisten a la audiencia, es claro que la sanción no es la multa, sino que incurren en causal de mala conducta, sancionable con destitución del cargo, previo el trámite disciplinario que corresponda e impuesta por el funcionario competente para ello (Camargo, 2003). Por las mismas razones, no puede asemejarse 0 asimilarse lo dispuesto en el Art. 41 a lo precisado en el Art. 27, dado que se trata de normas especiales que regulan temas claramente diversos, y más si se analiza que el Art. 41 , hace referencia al incumplimiento de "una orden judicial", en tanto que el Art. 27, además de puntualizar los efectos jurídicos que conlleva la inasistencia para el actor popular, simplemente contiene una "invitación" a las partes para que asistan a una audiencia.

Lo anterior significa que el legislador previó la posibilidad de la inasistencia de alguna de las partes, incluido el actor popular, a la audiencia de pacto, pero solo consideró sancionable la inasistencia del funcionario competente y esa interpretación es la que responde a la claridad de la norma, pues no impuso expresamente al actor popular ninguna sanción por su inasistencia. Por tal razón, la imposición de la multa al actor popular, mediante incidente, derivada del Art. 41 de la Ley 472 de 1998, resulta improcedente y por ende, en ese contexto, el Tribunal o el Consejo de Estado, en su caso, no tendría competencia para conocer del grado de consulta de una decisión adoptada con base en esa norma.

De otro lado, es claro que esta sanción no se ajustaría al principio de legalidad de la pena, al cual debe acudirse por referirse al ejercicio del poder de corrección o sancionador del juez, y el mismo deriva su importancia y encuentra sustento en el derecho fundamental del debido proceso, consagrado en el artículo 29 de la Constitución Política, aplicable a "toda clase de actuaciones judiciales y administrativas", en el sentido de que "nadie podrá ser juzgado sino conforme a leyes preexistentes al acto que se le imputa"; principio universalmente divulgado para efectos sancionatorios como nullum

3 La Ley 1437 de 2011, Por la cual se expide el Código de Procedimiento Administrativo y de lo Contencioso Administrativo, vigente desde el 2 de julio de 2012, suprimió el grado jurisdiccional de consulta para los procesos ordinarios contenciosos. Sin embargo, subsisten algunas disposiciones especiales que lo contemplan, como es el caso de la consulta para los casos en que se imponen sanciones. 
crimen sine previa lege, que impone la necesidad de la descripción legal de la conducta a sancionar y su consecuencia, a efectos de aplicar la consecuencia que esgrime la norma.

En tercer lugar, otro argumento que resulta de imposible olvido es que como se trata de una medida correctiva 0 sancionatoria, no pueden aplicarse analógicamente procedimientos que no están contemplados por el legislador, porque en materia sancionatoria rige el principio de la especialidad 0 taxatividad. En efecto, el principio de legalidad de las sanciones está complementado con el principio de tipicidad (Fernández, 1999) denominado por la Corte Constitucional en sentencia C-843-99, como de taxatividad penal, "según el cual las conductas punibles deben estar descritas inequívocamente y las sanciones a imponer deben estar también previamente determinadas"; en una frase, nulla poena sine previa lege; en el supuesto analizado no se cumpliría el principio de legalidad de la sanción ni el de la tipicidad de la conducta.

En cuanto a la analogía o remisión a los poderes correccionales del juez, consagrados en los artículos 74 de la Ley 446 de 1998, 39 y 101 del C.P.C. y 114 del C.C.A., a que se alude en algunas decisiones del Consejo de Estado, cabe mencionar que se hace una incorrecta referencia a estas normas, porque se trata de regulaciones exactas para los eventos allí previstos y jamás pueden utilizarse, vía analogía, para imponer una sanción pecuniaria de esta magnitud a los actores populares, que en últimas, su propósito no es otro que la protección judicial de unos derechos o intereses colectivos que en su criterio han sido vulnerados por la autoridad pública. La sentencia que podría esgrimirse como apoyo, ${ }^{4}$ simplemente contiene una obiter dicta, y en consecuencia, no puede tenerse como precedente aplicable y obligatorio al caso. ${ }^{5}$
Respecto a la "exhortación" que viene haciendo el Consejo de Estado en varias de sus decisiones, ${ }^{6}$ debe ser entendida en el contexto que gobierna en estos tiempos el derecho sancionatorio en su aspecto procesal así como en el sustantivo, esto es, en el sentido de establecer las circunstancias específicas del actor popular en cada proceso, incluyendo el análisis de sus descargos en punto de la consecuencia de su inasistencia y la razonabilidad de su justificación, porque en esta materia está erradicada desde hace mucho tiempo la imputación objetiva.

En armonía con lo anterior, al estudiar la doctrina universalmente aceptada en materia penal, cuyos principios es preciso tener en cuenta por tratarse en el sub lite de la imposición de una "sanción", se aboga por que no se renuncie y más bien que se exija al juez "la permanente confrontación de las normas positivas y de las teorías penales con las otras normas del sistema...con las valoraciones contenidas en las normas o principios de la propia ley...en la Constitución y en los tratados...", para darle un "sentido" y no solamente atender a su contenido lógico gramatical, salvo en los contenidos abiertos del derecho, pero que en todo caso, sobre esto último, "nada de ello autoriza al operador jurídico a abandonar la ley, ni pude conducirlo a hacer política criminal”. (Fernández, 2002:87)

Por tanto, establecidas esas circunstancias específicas de la conducta omisiva del actor popular que incumple la cita a la audiencia de pacto de cumplimiento, debe sopesarse la razón por la cual no pudo asistir con un criterio de razonabilidad y proporcionalidad, teniendo en cuenta el daño que su inasistencia causa al proceso, pues sin haberse establecido ese daño, pierde sentido la magnitud de la sanción impuesta, tasada como mínimo en dos salarios mínimos legales mensuales vigentes.

4 Se alude a la sentencia del 6 de octubre de 2005, magistrada ponente María Claudia Rojas Lasso.

5 Sobre la obligatoriedad del precedente judicial, deben examinarse sin excusa, las sentencias C-543 de 1992, T-260 de 1995, C-083 de 1995, T-571 de 2007 y C-335 de 2008 de la Corte Constitucional

6 Colombia, Consejo de Estado, Sala de lo Contencioso Administrativo, Sección Primera, sentencia del 29 de julio de 2010. Consejera Ponente María Claudia Rojas Lasso, Expediente 15001-23-31-000-2003-01857-01(AP). También la decisión del 5 de febrero de 2009, expediente 2003-01097-01 de la misma ponente y sentencia del 30 de agosto de 2007, expediente Rad. 20040143(AP), consejero Ponente Marco Antonio Velilla Moreno. 
En razón de lo anterior, la decisión que se profiera en ese sentido no encuentra sustento jurídico alguno y en grado jurisdiccional de consulta, de ser viable esta instancia, debe dejarse sin ningún efecto.

\section{CONCLUSIONES}

El estudio realizado permite concluir que aún en vigencia de las Leyes 1437 de 2011 y 1564 de 2012, la decisión judicial mediante la cual el juez de primera instancia impone sanción pecuniaria -multa- al actor popular por no asistir a la audiencia especial de pacto de cumplimiento, como acto procesal de trámite 0 impulso de las acciones populares, es improcedente y resulta contrario al principio de legalidad, al debido proceso y el derecho de defensa.

Se demostró que si el legislador no distinguió y definió un aspecto tan importante, que tiene que ver con pilares fundamentales de la organización judicial colombiana, el intérprete no puede hacerlo y en el caso concreto, el juez no podría sancionar al actor popular por ese hecho.

Además, según lo entiende un gran sector de la doctrina nacional, el punto del poder de corrección y sancionador del Estado -concretado en los jueces que tramitan las acciones populares- no debe perderse de vista que para cada caso, es necesario examinar las razones por las cuales el actor popular no asiste a dicha audiencia, con un criterio de razonabilidad y proporcionalidad, teniendo en cuenta el daño que su inasistencia causa al proceso.

Igualmente, se expusieron las razones 0 argumentos jurídicos que indican la improcedencia del grado jurisdiccional de la consulta del auto que así lo disponga, pues dicha instancia no está prevista en la ley.

\section{REFERENCIAS BIBILIOGRÁFICAS}

- Bejarano Guzmán, R. (1999). De las acciones populares y de grupo. Obra colectiva reformas a la Legislación Mercanti. Colegio de Abogados de Medellín Edit. Dike, 1999

- Botero, L. (2004). Acción popular y nulidad de actos administrativos. Protección de derechos colectivos. $1^{\mathrm{a} e d .}$. Bogotá, Colombia: Editorial Legis.
- Camargo, P. (2003). Las acciones Populares y de Grupo. $4^{\mathrm{a} e d .}$. Bogotá, Colombia: Editorial Leyer.

- Camargo, P. (2005). El Debido Proceso. $3^{\mathrm{a}} \mathrm{ed}$. Bogotá, Colombia: Editorial Leyer.

- Defensoría del Pueblo.(1994). Acciones populares y de grupo. Memorias. Seminario Internacional de acciones populares y de grupo. Bogotá, Colombia: Ediciones Jurídicas Gustavo Wilches.

- Fernández Carrasquilla, J. (1999). Principios y normas rectoras del Derecho Penal, Bogotá, Colombia: Editorial Leyer.

- Fernández Carrasquilla, J. (2002). Derecho Penal Liberal de Hoy. Bogotá, Colombia: Ediciones Jurídicas Gustavo Ibáñez,

- Palacio, J. (2013). Derecho Procesal Administrativo $8^{a}$ ed. Medellín, Colombia: Editorial Librería Jurídica Sánchez.

- Ramírez Bastidas, Y. \& De Ramírez, R. (2002). Principialística Procesal Penal. Bogotá, Colombia: Ediciones Jurídicas Gustavo Ibáñez,

- Sarmiento Palacios, G. (1989). Las acciones populares en el derecho privado. Cabildo, No. 14.

- Sarmiento, G. (1989). Las acciones populares en el derecho privado. Cabildo, No. 14.

- Tamayo Jaramillo, J. (2001). Las acciones populares y de grupo en la responsabilidad civil.

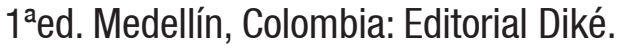

- Vila Casado, I. (2007). Fundamentos del derecho constitucional contemporáneo. $1^{\mathrm{a} e d . ~ B o g o t a ́, ~}$ Colombia: Editorial Legis.

\section{REFERENCIAS JURISPRUDENCIALES}

- CCons, C-543/1992, J. Hernández.

- CCons, T-260/1995, J. Hernández.

- CCons, T-571/2007, J. Córdoba.

- CCons, C-335/2008, H. Sierra.

- CCons, C- 63072011, M. Calle.

- CE1, 30 Ago. 2007, r2004-0143(AP). M. Velilla

- CE1, 5 Feb. 2009, r2003-01097-01. M. Rojas

- CE1, 29 Jul. 2010. r2003-01857-01(AP).M. Rojas

\section{REFERENCIAS NORMATIVAS}

- C.N.

- L. 472/1998.

- L. $1437 / 2011$.

- L. $1564 / 2012$. 